\title{
A Comparison Of The Antibacterial Efficiency Of MTAD (Mixture Of Tetracycline, Citric Acid And Detergent), 2.5\% Sodium Hypochlorite And 2\% Chlorhexidine Root Canal Irrigants Against Enterococcus Faecalis In Root Canals Of Single Rooted Mandibular Premolars- An In Vitro Study
}

\author{
Ramta Bansal ${ }^{1}$, Aditya Jain ${ }^{2}$, Sunandan $\mathrm{Mittal}^{3}$,Tarun $\mathrm{Kumar}^{4}$, Neerja Jindal ${ }^{5}$ \\ ,Dilpreet Kaur ${ }^{6}$ \\ ${ }^{1}$ Senior Lecturer,Department of Conservative Dentistry and Endodontics Institute of Dental sciences Sehora \\ Jammu, India \\ ${ }^{2}$ Lecturer, Department Of Physiology Government Medical College Patiala( Punjab), India \\ ${ }^{3,4}$ Department of Conservative dentistry and Endodontics DIRDS, Faridkot - Punjab, India \\ ${ }^{5}$ Department of Microbiology Guru Gobind Singh Medical College \& Hospital, Faridkot. Punjab, India \\ ${ }^{6}$ Department of Conservative dentistry and Endodontics Bhojia Dental College \& Hospital(Baddi),H.P,India
}

\begin{abstract}
Introduction: Historically, countless compounds in aqueous solution have been suggested as root canal irrigants. MTAD shows promise as an endodontic irrigant but there are very few studies comparing its antimicrobial effectiveness with $\mathrm{NaOCl}$ and Chlorhexidine.

Objectives: To compare the antibacterial efficiency of MTAD, 2.5\% Sodium Hypochlorite and 2\% Chlorhexidine root canal irrigants against Enterococcus faecalis in root canals of single rooted mandibular premolars.

Method: Inoculum of $10 \mu \mathrm{l}, 24 \mathrm{hrs}$ pure culture Enterococcus faecalis was suspended into root canals of forty extracted, decoronated, double sterilized, human mandibular single rooted premolar teeth and incubated for $48 \mathrm{hrs}$ at $37^{\circ} \mathrm{C}$. Teeth were randomly divided into 4 groups of 10 teeth in each group. The teeth were instrumented in step back technique till size $40 \mathrm{~K}$ - file and irrigated with respective root canal irrigants as per the groups. In Group A- MTAD, Group B- 2.5\% NaOCl, Group C- $2 \%$ Chlorhexidine and Group D- normal saline was used. Bacterial sample from each tooth was collected and bacterial culture was carried out using standard Loop technique. Inoculated plates were incubated at $37^{\circ} \mathrm{C}$ for $48 \mathrm{hrs}$. Bacterial colonies were counted using colony counter.
\end{abstract}

Statistically Analysed: Using One way ANOVA and LSD Post Hoc test.

Results: There was a statistically significant difference in the antibacterial efficiency between all the groups.

Conclusion: Within limitations of this study it can be inferred that MTAD has best antibacterial efficiency against Enterococcus faecalis when compared to 2.5\% Sodium Hypochlorite and 2\% Chlorhexidine.

Keywords: Chlorhexidine; Enterococcus faecalis; Irrigants; MTAD; Sodium Hypochlorite.

I. Introduction:

Although chemo-mechanical preparation of the root canal system is able to reduce the number of bacteria, complete canal disinfection is difficult because of the internal complexity of root canal systems $[1,2]$. Thus root canal irrigation forms an integral part of the endodontic therapy to ensure bacterial elimination $[3,4]$ and for the digestion of the organic tissue remnants as it allows for cleaning beyond what might be achieved by root canal instrumentation alone [5,6].

According to Zehnder (2006)[7] root canal irrigants ideally should:

- Have a broad antimicrobial spectrum and high efficacy against anaerobic and facultative microorganisms organized in biofilms

- Dissolve necrotic pulp tissue remnants

- Inactivate endotoxin

- Prevent the formation of a smear layer during instrumentation or dissolve the smear layer once it has formed

Furthermore, as endodontic irrigants come in contact with vital tissues, they should be systemically nontoxic, non-caustic to periodontal tissues and have little potential to cause an anaphylactic reaction.

Historically, countless compounds in aqueous solution have been suggested as root canal irrigants. Prior to 1940's Water was the most commonly used irrigant. During 1940's proteolytic enzymes like streptokinase, 
streptodomase, papain, enzymal etc. were used as irrigating solutions because of their tissue dissolving property. In 1943, Grossman introduced the concept of using oxidizing agents (hydrogen peroxide and Gly-Oxide) as irrigants. In 1945, Daniel formulated an irrigating solution comprising of aminoacridine. In 1970's chelating agents (EDTA) were used increasingly because of their biologically acceptable properties. Other irrigants include acids (citric and phosphoric), alkaline solutions (sodium hypochlorite, sodium hydroxide, urea and potassium hydroxide), local anaesthetic solutions and normal saline [8].

Sodium hypochlorite $(\mathrm{NaOCl})$ has been widely used as an irrigant since its introduction in endodontics by Walker (1936)[9]. It has been recommended as an irrigant solution in the treatment of infected root canals because of its well-known bactericidal action [10, 11, 12]. The major disadvantages of $\mathrm{NaOCl}$ are: (a) significant toxicity when injected into peri-radicular tissues (b) disagreeable smell and taste (c) risk of bleaching clothes (d) corrosion of metal objects [13] (e) inability to remove smear layer when used alone [14,15]. The biocompatibility problems associated with the use of concentrated $\mathrm{NaOCl}$ have led to the use of substances with known antimicrobial properties and less toxicity, such as chlorhexidine.

Chlorhexidine is bacteriostatic at low concentrations of $0.2 \%$, bactericidal at high concentrations of $2 \%$ , adsorbs to dental tissue and mucous membrane, resulting in its prolonged gradual release at therapeutic levels [16] and is effective in eliminating bacteria penetrate up to $500 \mu \mathrm{m}$ within dentinal tubules [17]. Despite its usefulness as a antimicrobial irrigant with low toxicity, Chlorhexidine cannot be advocated as the main irrigant in standard endodontic cases, because: (a) Chlorhexidine is unable to dissolve necrotic tissue remnants [18] (b) Chlorhexidine is less effective on Gram-negative than on Gram-positive bacteria [19, 20].

A new irrigating solution, MTAD, containing a mixture of a tetracycline isomer, an acid and a detergent, has demonstrated its ability to remove the smear layer, disinfect contaminated root canals and eradicate E. faecalis $[21,22,23]$. There is no doubt MTAD has good antimicrobial properties but there are very few studies comparing its antimicrobial effectiveness with $\mathrm{NaOCl}$ and Chlorhexidine. It is by no means clear if it is better than $\mathrm{NaOCl}$ and Chlorhexidine as an endodontic irrigant.

The intent of the current study was to compare the antibacterial efficiency of MTAD (Mixture of Tetracycline, Citric Acid and Detergent), 2.5\% Sodium Hypochlorite and 2\% Chlorhexidine root canal irrigants against Enterococcus faecalis in root canals of single rooted mandibular premolars. Our design allowed direct comparison of each irrigant against Enterococcus faecalis.

\section{Materials and methods}

The study was carried in the Post graduate section of Department of Conservative Dentistry and Endodontics, Dasmesh Institute of Research and Dental Sciences, Faridkot, Punjab, India. Forty extracted human mandibular single rooted premolar teeth $(n=40)$, non carious with matured, closed apices were collected from the oral surgery Department of Dasmesh Institute of Research and Dental Sciences, Faridkot, Punjab, India. Each tooth was radiographed to confirm for the presence of a single canal. All the teeth were decoronated with a diamond disc using a low speed straight hand piece (NSK EX-6B, Nakanishi Inc. Japan), so as to standardize roots of all the teeth (approximately $14 \mathrm{~mm}$ ) to the same length. Working lengths for all the teeth were determined using a size 15 K-files (Dentsply, Germany), measured with help of Mini Endo-block (endogauge)( Maillefer, Dentsply Switzerland) and radiographs were taken and recorded. Then all the teeth were double sterilized in an autoclave at a temperature of $121^{\circ} \mathrm{C}$ under $15 \mathrm{lbs}$ of pressure for 20 minutes. The bacterial strain used in the present study was E. faecalis (ATCC 29212). It was grown in Brain Heart Infusion (BHI) (Himedia Laboratories. Pvt. Ltd, Mumbai, India) broth for $24 \mathrm{hrs}$ at $37^{\circ} \mathrm{C}$. An inoculum of $10 \mu \mathrm{l}, 24 \mathrm{hrs}$ pure culture suspension of $\mathrm{E}$. faecalis was suspended into root canals of all the teeth by using a tuberculin syringe (Romsons juniors India unit II Agra, India) inside the laminar air flow under fully aseptic conditions. Later each tooth was transferred carefully into a test tube containing $4 \mathrm{ml}$ of sterile normal saline and incubated for $48 \mathrm{hrs}$ at temperature of $37^{\circ} \mathrm{C}$. After incubation, the teeth were removed from the test tubes and were rinsed thoroughly with sterile normal saline. All the teeth were then randomly divided into four test groups $(\mathrm{n}=10$ each) and each group was irrigated with different irrigants.

Group A: MTAD (Dentsply Tulsa Dental, Dentsply international, Inc. Tulsa, United States) was used as irrigant

Group B: $2.5 \%$ Sodium hypochlorite (Prevest Denpro Limited Jammu, India) was used as irrigant. $2.5 \%$ Sodium hypochlorite was prepared from $5 \%$ Sodium hypochlorite by adding distilled water to it in ratio 1:1. Group C: 2\% Chlorhexidine (Septodent Healthcare India Pvt. Ltd. Maharashtra, India) was used as irrigant Group D: Normal saline (Nirma Limited Gujarat, India) was used as irrigant

Group A: Here only MTAD was used as root canal irrigant.

As per the working lengths determined, root canals of all the teeth were instrumented with step back technique and the canals were enlarged using K-file upto size 40 no. K-file. During the process of instrumentation, canals were irrigated with $2 \mathrm{ml}$ of MTAD per tooth. Following completion of instrumentation, a final rinse of each root 
canal was carried out by using $5 \mathrm{ml}$ of MTAD for 5 minutes. After accomplishing the removal of excess moisture from the canal with help of size 35 no. absorbent paper point (Maillefer, Dentsply, China ), a dry sterile standardized absorbent paper point of size 40 was kept in the root canal to the full working length for 10 seconds. Later the paper point was taken out and transferred into a test tube containing $2 \mathrm{ml}$ sterile normal saline and was vortexed for $1 \mathrm{~min}$. Then from each test tube sample, bacterial culture was carried out using a standard Loop technique for semiquantitative culture on 5\% sheep blood agar and the inoculated plates were incubated at $37^{\circ} \mathrm{C}$ for $48 \mathrm{hrs}$ under aerobic conditions. This entire procedure was carried out in complete aseptic conditions. Finally with help of colony counter bacterial colonies were counted.

Group B: The entire procedure was carried out just similar to that of Group A, except that instead of MTAD, $2.5 \% \mathrm{NaOCl}$ was used as root canal irrigant.

Group C: The same procedure was carried out here also as described for Group A, except that irrigation was carried out using $2 \%$ Chlorhexidine.

Group D: The same procedure was carried out as described for Group A, except that sterile normal saline was used as an irrigant.

Counting of the Colony forming units (C.F.U) per plate for all groups was done.The results were statistically analysed.

\section{Observations and Results}

Counting of the Colony forming units (C.F.U) per plate for all groups was done. The results were statistically analysed. Group A had colony forming units (C.F.U) in the range 5-16 while the group B showed 17-61 range of colony forming units. Group C had 62-130 whereas group D showed highest range of 72-296 colony forming units.

One way ANOVA analysis among the four groups is shown in Table 1.

Table 1: One Way Anova Analysis

\begin{tabular}{|cccc|}
\hline Group & Range & Mean \pm SD & One-Way ANOVA \\
\hline A & $5-16$ & $9.30 \pm 3.06$ & $\mathrm{~F}=20.985$ \\
B & $17-61$ & $44.80 \pm 13.18$ & $\mathrm{p}<0.001 * *$ \\
C & $62-130$ & $81.60 \pm 22.46$ & \\
D & $72-296$ & $138.30 \pm 71.42$ & \\
& & $\mathrm{~F}=$ F-ratio \\
& $* \mathrm{p}<0.01 ;$ Significant \\
& & $* * \mathrm{p}<0.001 ;$ Highly significant \\
\end{tabular}

In Table 1 we see an F-ratio $(\mathrm{F})$ of 20.985 ( $\mathrm{p}<0.001$ ). This $\mathrm{p}(\mathrm{F})$ tells that there is highly significant difference among the four groups of root canal irrigants. Overall group comparisons of p value was done using Post-hoc LSD test as shown in Table 2.

Table 2: Overall Group Comparisons of p Value

\begin{tabular}{cc} 
Group Comparisons & p value (Using Post-hoc LSD) \\
\hline A vs. B & $\mathbf{0 . 0 4 4}$ \\
A vs. C & $<0.001^{* *}$ \\
A vs. D & $<\mathbf{0 . 0 0 1} * *$ \\
B vs. C & $0.037^{*}$ \\
B vs. D & $<0.001^{* *}$ \\
C vs. D & $\mathbf{0 . 0 0 2} *$
\end{tabular}

$$
\begin{gathered}
* \mathrm{p}<0.01 ; \text { Significant } \\
* * \mathrm{p}<0.001 ; \text { Highly significant }
\end{gathered}
$$

Thus if the groups are overall compared with each other (Fig. 1\&2) for antibacterial activity, it can be concluded that group A (MTAD alone was used as an irrigant), shows the maximum efficiency against Enterococcus faecalis, followed by group $\mathrm{B}$ (only $2.5 \% \mathrm{NaOCl}$ was used as an irrigant) and the least effective is the control group D where only saline was used as an irrigant. 


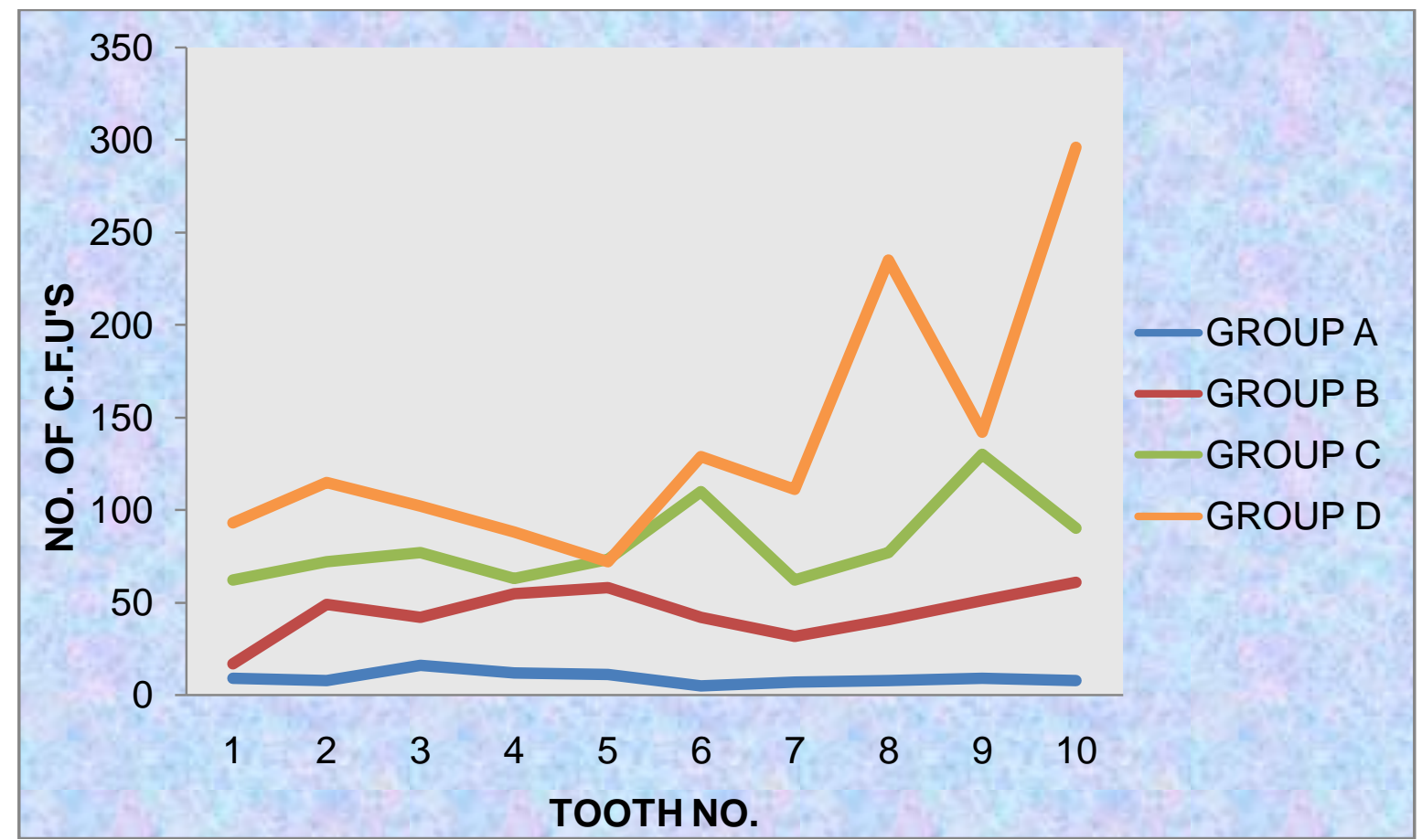

Figure 1: comparison of number of C.F.U'S among all groups

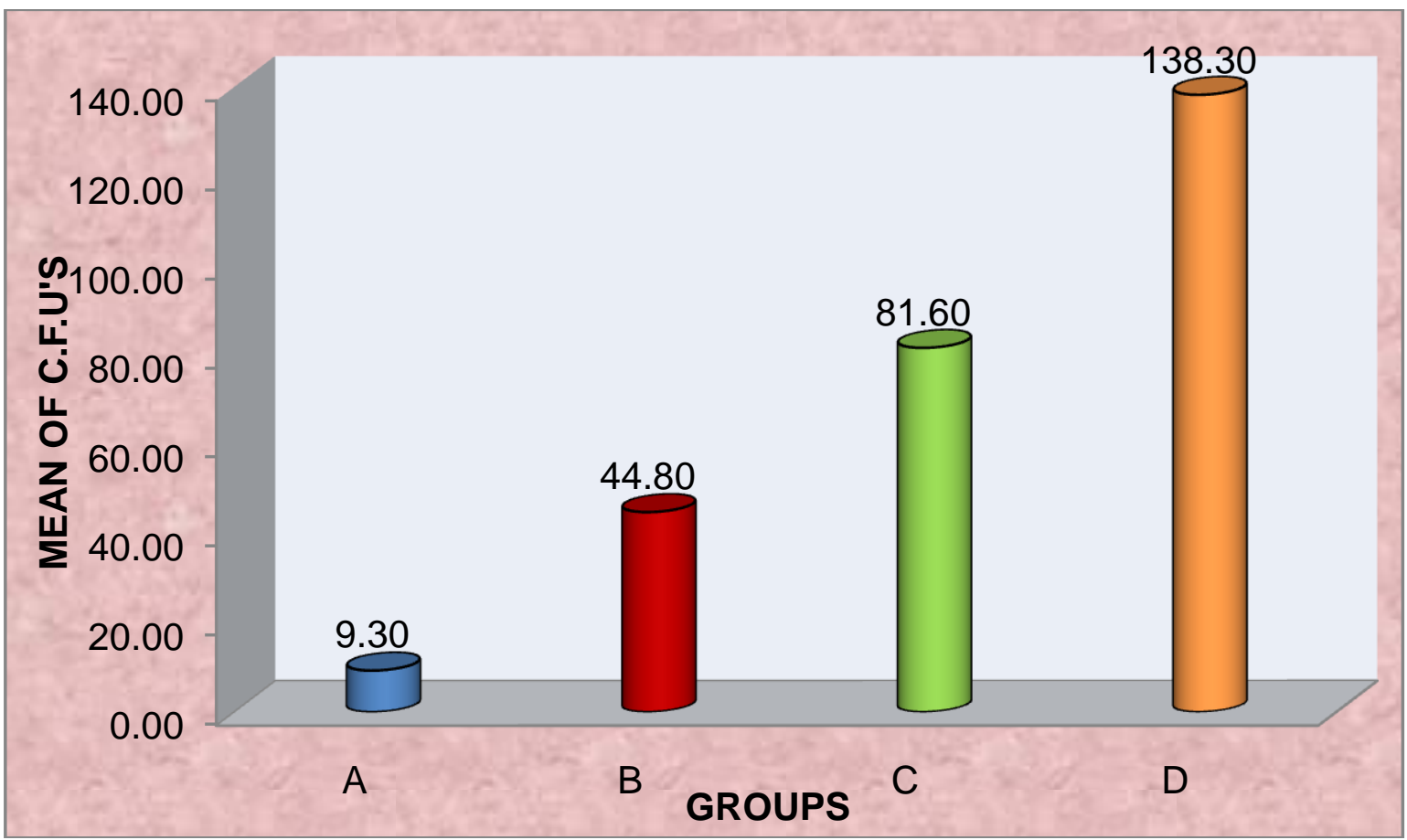

Figure 2: mean of C.F.U'S in all groups

\section{Discussion:}

E. faecalis was chosen as the primary test organism because it is the most resistant bacteria found in the root canal system and has been associated with treated root canal failures. Its prevalence in such infections ranges from $24-77 \%$ [24]. It was also chosen because recent studies claimed that MTAD is an effective final irrigating solution for eradication of E. faecalis [22,25].

$2.5 \%$ concentration of $\mathrm{NaOCl}$ was used because $\mathrm{NaOCl}$ is highly toxic to vital tissues at undiluted high concentrations. At higher concentration, for example, 1:10 (vol/vol) dilution, the tissue irritation may be substantial [26] and displacing highly concentrated $\mathrm{NaOCl}$ into periapical tissues can cause severe tissue damage [27]. Also there is some dispute regarding the most effective concentration of $\mathrm{NaOCl}$, although 
theoretically the concentration should be kept to the lowest level that is effective. When used in contaminated canals of extracted teeth, Siqueira et al. (2000)[28] found no difference in the antibacterial effect of 1\%, $2.5 \%$ and $5.2 \% \mathrm{NaOCl}$. They suggested that copious irrigation with $\mathrm{NaOCl}$ may maintain a chlorine reserve that is sufficient to eliminate bacterial cells and compensate for the effect of concentration. Berber et al. (2006) [29] found no differences among various concentrations of $\mathrm{NaOCl}$ in reducing $\mathrm{E}$ faecalis within root canals and dentinal tubules but only at the higher concentrations was $\mathrm{NaOCl}$ able to disinfect the dentinal tubules independent of the canal preparation technique used. Others also demonstrated that lower concentrations are as effective or ineffective in eliminating bacteria [30]. Since the proteolytic effect of $\mathrm{NaOCl}$ is dependent on the amount of free available chlorine that is used up during the process by reacting with inorganic reducing substances, frequent irrigation with a lower concentration may achieve as much of a proteolytic effect as the use of a higher concentration [28]. In the light of these clinical studies, it can be concluded that the $\mathrm{NaOCl} \mathrm{has} \mathrm{an}$ efficient antimicrobial effect at low concentration and it shows proportional increase in toxicity with higher concentration with no demonstrable clinical effectiveness.

$2 \%$ concentration of Chlorhexidine was chosen for study because chlorhexidine is bacteriostatic at low concentrations of $0.2 \%$. At high concentrations of $2 \%$ chlorhexidine is bactericidal and adsorbs to dental tissue and mucous membrane, resulting in its prolonged gradual release at therapeutic levels [16]. Aqueous solutions of 0.1 to $0.2 \%$ are recommended for chemical plaque control in the oral cavity, while $2 \%$ is the concentration of root canal irrigating solutions usually found in the endodontic literature [31].

In this study only MTAD (i.e. without initial use of $1.3 \% \mathrm{NaOCl}$ ) was compared for its antimicrobial efficiency because studies have shown that the cleanest canals were obtained if $\mathrm{NaOCl}$ was used before a final soak and flush with MTAD [25]. The studies comparing the antimicrobial effect of MTAD alone (i.e. without initial use of $1.3 \% \mathrm{NaOCl}$ ) with other irrigants are lacking.

The results of present study show that for the group comparison of A vs. B, the p value is 0.044 which is significant. Thus irrigant of group A i.e. MTAD has better antibacterial activity than irrigant of group B i.e. $2.5 \%$ Sodium Hypochlorite. Similarly p value for comparison of group A vs. C and group A vs. D is $<0.001$ which is highly significant indicating that antibacterial efficacy of MTAD is much better than 2\% Chlorhexidine and normal saline respectively.

$\mathrm{p}$ value for group comparison of B vs. C is 0.037 which is significant. Thus irrigant of group B i.e. 2.5 $\%$ Sodium Hypochlorite has better antibacterial efficacy than irrigant of group C i.e. $2 \%$ Chlorhexidine. For the group comparison of $\mathrm{B}$ vs. $\mathrm{D}$, the $\mathrm{p}$ value is $<0.001$ which is highly significant indicating that antibacterial efficacy of $2.5 \%$ Sodium Hypochlorite is much better than Normal saline.

The results show that for the group comparison of $\mathrm{C}$ vs. D, the $\mathrm{p}$ value is 0.002 which is significant. Thus irrigant of group $\mathrm{C}$ i.e. $2 \%$ Chlorhexidine has better antibacterial activity than irrigant of group D i.e. Normal saline.

Thus if the groups are overall compared with each other for antibacterial activity, it can be concluded that group A (MTAD alone was used as an irrigant), shows the maximum efficiency against Enterococcus faecalis, followed by group $\mathrm{B}$ (only $2.5 \% \mathrm{NaOCl}$ was used as an irrigant) and the least effective is the control group D where only saline was used as an irrigant.

Torabinejad et al. (2003)[25] found MTAD was effective in killing E. faecalis up to $200 \mathrm{x}$ dilution whereas $\mathrm{NaOCl}$ ceased to exert its antibacterial activity beyond $32 \mathrm{x}$ dilution. Shabahang \& Torabinejad (2003) [21] showed that the combination of $1.3 \% \mathrm{NaOCl}$ as a root canal irrigant and MTAD as a final rinse was significantly more effective against E. faecalis than the other regimens. Newberry et al. (2007) [32] showed that MTAD in conjunction with $1.3 \% \mathrm{NaOCl}$ was effective in completely eliminating growth in 7 of 8 strains of E. faecalis. Similar to these results, Davis et al. (2007)[33] found that MTAD showed significantly more zones of microbial inhibition for E. Faecalis than $\mathrm{NaOCl}$, Chlorhexidine and Dermacyn (a superoxidized water).

The results of the our study done agree with these in-vitro studies and indicate that MTAD has better antibacterial activity than $2.5 \%$ sodium hypochlorite and $2 \%$ Chlorhexidine.

However there are certain studies that display less than optimal antimicrobial activity of MTAD. Kho \& Baumgartner (2006)[34] demonstrated no difference in antimicrobial efficacy for irrigation with $5.25 \%$ $\mathrm{NaOCl} / 15 \%$ EDTA versus irrigation with $1.3 \% \mathrm{NaOCl} / \mathrm{MTAD}$ in the apical $5 \mathrm{~mm}$ of roots infected with $\mathrm{E}$. faecalis. Dunavant et al. (2006) [35]found that $6 \%$ and $1 \% \mathrm{NaOCl}$ were significantly more efficient in eliminating E. faecalis biofilms than other irrigants such as $2 \% \mathrm{CHX}$, MTAD and commercial preparations of EDTA. A study by Baumgartner et al. (2007)[36] found no growth of E. faecalis in root canals irrigated with $5.25 \% \mathrm{NaOCl} / 15 \%$ EDTA, whereas $50 \%$ of the canals irrigated with $1.3 \% \mathrm{NaOCl} / \mathrm{MTAD}$ demonstrated growth of E. faecalis. Less than optimal antibacterial effect of MTAD in these studies could be because of the difference in simulated clinical conditions, methodology, microbial sampling procedures or because of difference in the study model. 


\section{Conclusion}

Within the limitations of this study the following conclusions can be inferred that MTAD has best antibacterial efficiency against Enterococcus faecalis when compared to 2.5\% Sodium Hypochlorite and 2\% Chlorhexidine. Further studies are required to prove the efficiency of MTAD in clinical situations. The conclusions of the present work are limited to the in vitro conditions of the study and should be confirmed by further in vivo investigations.

\section{References:}

[1]. Bystrom A, Sundqvist G.Bacteriologic evaluation of the efficacy of mechanical root canal instrumentation in endodontic therapy. Scandinavian Journal of Dental Research, 89(4), 1981, 321- 8.

[2]. Siqueira JF Jr, Lima KC, Magalhaes FA, Lopes HP D. Mechanical reduction of the bacterial population in the root canal by three instrumentation techniques. Journal of Endodontics, 25(5), 1999, 332-5.

[3]. Jeansonne MJ, White RR. A comparison of $2.0 \%$ chlorhexidine gluconate and $5.25 \%$ sodium hypochlorite as antimicrobial endodontic irrigants. Journal of Endodontics, 20(6), 1994, 276-8.

[4]. Kuruvilla JR, Kamath MP. Antimicrobial activity of $2.5 \%$ sodium hypochlorite and $0.2 \%$ chlorhexidine gluconate separately and combined, as endodontic irrigants. Journal of Endodontics, 24(7), 1998, 472-6.

[5]. Svec TA, Harrison JW. Chemo-mechanical removal of pulpal and dentinal debris with sodium hypochlorite and hydrogen peroxide vs normal saline solution. Journal of Endodontics, 3(2), 1977, 49-53.

[6]. Gulabivala K, Patel B, Evans G, Ng YL. Effects of mechanical and chemical procedures on root canal surfaces. Endodontic Topics, $10,2005,103-22$.

[7]. Zehnder M. Root Canal Irrigants. Journal of Endodontics, 32(5), 2006, 389-398.

[8]. Becker TD, Woollard GW. Endodontic irrigation. General dentistry, 49, 2001, 272-6.

[9]. Walker A. Definite and dependable therapy for pulpless teeth. Journal of American Dental Association, 23, 1936, 1418-24.

[10]. Shih M, Marshall FJ, Rosen S. The bactericidal efficiency of sodium hypochlorite as an endodontic irrigant. Oral Surgery, Oral Medicine and Oral Pathology, 29(4), 1970, 613-19.

[11]. Bloomfield SF, Miles GA. The antibacterial properties of sodium dichloroisocyanurate and sodium hypochlorite formulations. Journal of Applied Bacteriology, 46(1), 1979, 65-73.

[12]. Foley DB, Weine FS, Hagen JC. Effectiveness of selected irrigants in the elimination of Bacteroides melaninogenicus from the root canal system: an in vitro study. Journal of Endodontics, 9(6), 1983, 236-41.

[13]. Gomes BP, Ferraz CC, Vianna ME, Berber VB, Teixeira FB, Souza-Filho FJ. In vitro antimicrobial activity of several concentrations of sodium hypochlorite and Chlorhexidine gluconate in the elimination of Enterococcus faecalis. International Endodontic Journal, 34(6), 2001, 424-8.

[14]. McComb D, Smith DC. A preliminary scanning electron microscopic study of root canals after endodontic procedures. Journal of Endodontics, 1, 1975, 238-42.

[15]. Goldman LB, Goldman M, Kronman JH, Lin PS. The efficacy of several irrigating solutions for endodontics: a scanning electron microscopic study. Oral Surgery, Oral Medicine \& Oral Pathology, 52(2), 1981, 197-204.

[16]. White RR, Hays GL, Janer LR. Residual antimicrobial activity after canal irrigation with Chlorhexidine. Journal of Endodontics, 23(4), 1997,229-31.

[17]. Heling I, Sommer M, Steinberg D, Friedman M, Sela MN. Microbiological evaluation of the efficacy of chlorhexidine in a sustained-release device for dentine sterilization. International Endodontic Journal, 25(1), 1992, 15-9.

[18]. Naenni N, Thoma K, Zehnder M. Soft tissue dissolution capacity of currently used and potential endodontic irrigants. Journal of Endodontics, 30(11), 2004, 785-7.

[19]. Hennessey TS.Some antibacterial properties of chlorhexidine. Journal of Periodontal Research Supplement, 12, 1973, 61-7.

[20]. Emilson CG.Susceptibility of various microorganisms to Chlorhexidine. Scandinavian Journal of Dental Research, 85(4), 1977, $255-65$.

[21]. Shabahang S, Torabinejad M. Effects of MTAD on Enterococcus Faecalis contaminated root canals of extracted human teeth. Journal of Endodontics, 29(9), 2003, 576-9.

[22]. Shabahang S, Pouresmail M, Torabinejad M. In vitro antimicrobial efficacy of MTAD and sodium hypochlorite. Journal of Endodontics,29(7), 2003, 450-2.

[23]. Torabinejad M, Khademi AA, Babagoli J, Cho Y, Johnson WB, Bozhilov K et al. A new solution for the removal of smear layer. Journal of Endodontics,29(3), 2003,170-5.

[24]. Stuart CH, Schwartz SA, Beeson TJ, Owatz CB. Enterococcus faecalis: its role in the root canal treatment failure and current concepts in retreatment. Journal of Endodontics, 32(2), 2006, 93-8.

[25]. Torabinejad M, Shabahang S, Aprecio, Raydolfo M, Kettering, James D. The antimicrobial effect of MTAD: an in vitro investigation. Journal of Endodontics, 29(6), 2003,400-3.

[26]. Pashley EL, Birdsong NL, Bowman K, Pashley DH. Cytotoxic effects of NaOCl on vital tissue. Journal of Endodontics, 11(12), 1985, 525-8.

[27]. Hulsmann M, Hahn W. Complications during root canal irrigation-literature review and case reports. International Endodontic Journal, 33(3), 2000, 186-93.

[28]. Siqueira JF Jr, Rocas IN, Favieri A, Lima KC.Chemo-mechanical reduction of the bacterial population in the root canal after instrumentation and irrigation with 1\%, 2.5\%, and 5.25\% sodium hypochlorite. Journal of Endodontics, 26(6), 2000, 331- 4.

[29]. Berber VB, Gomes BP, Sena NT, Vianna ME, Ferraz CC, Zaia AA et al. Efficacy of various concentrations of $\mathrm{NaOCl}$ and instrumentation techniques in reducing Enterococcus faecalis within root canals and dentinal tubules. International Endodontic Journal,39(1), 2006,10-7.

[30]. Shuping GB, Orstavik D, Sigurdsson A, Trope M.Reduction of intracanal bacteria using nickel-titanium rotary instrumentation and various medications. Journal of Endodontics, 26(12), 2000, 751-5.

[31]. Zamany A, Safavi K, Spangberg LS. The effect of chlorhexidine as an endodontic disinfectant. Oral Surgery, Oral Medicine, Oral Pathology, Oral Radiology and Endodontics,96(5), 2003, 578-81.

[32]. Newberry BM, Shabahang S, Johnson N, Aprecio RM, Torabinejad M.The Antimicrobial Effect of Biopure MTAD on Eight Strains of Enterococcus faecalis: An In Vitro Investigation. Journal of Endodontics,33(11), 2007, 1352-4. 
[33]. Davis JM, Maki J, Bahcall JK. An In Vitro Comparison of the Antimicrobial Effects of Various Endodontic Medicaments on Enterococcus faecalis. Journal of Endodontics, 33(5), 2007, 567-9.

[34]. Kho P, Baumgartner JC. A Comparison of the Antimicrobial Efficacy of NaOCl/Biopure MTAD versus NaOCl/EDTA against Enterococcus faecalis. Journal of Endodontics,32(7), 2006, 652-5.

[35]. Dunavant TR, Regan JD, Glickman GN, Solomon ES, Honeyman AL. Comparative evaluation of endodontic irrigants against Enterococcus faecalis biofilms. Journal of Endodontics, 32(6), 2006, 527-31.

[36]. Baumgartner JC, Johal S, Marshall JG. Comparison of the Antimicrobial Efficacy of $1.3 \% \mathrm{NaOCl} / \mathrm{BioPure} \mathrm{MTAD}$ to 5.25\% $\mathrm{NaOCl} / 15 \%$ EDTA for Root Canal Irrigation. Journal of Endodontics, 33(1), 2007, 48-51. 